\title{
INVESTIGATION OF SEVERAL GRAPHITE-BASED ELECTRODES FOR VANADIUM REDOX FUEL CELL
}

\author{
A. Di Blasi ${ }^{\mathrm{a}}$, O. Di Blasi ${ }^{\mathrm{a}}$, N. Briguglio ${ }^{\mathrm{a}}$, A. S. Aricò ${ }^{\mathrm{a}}$, D. Sebastián ${ }^{\mathrm{b}}$, \\ M. J. Lázaro ${ }^{\mathrm{b}}$, G. Monforte ${ }^{\mathrm{a}}$, V. Antonucci ${ }^{\mathrm{a}}$. \\ ${ }^{a}$ CNR ITAE, Salita S. Lucia sopra Contesse, 5 - 98126 Messina, Italy \\ b Instituto de Carboquímica CSIC, Miguel Luesma Castán 4, 50018 Zaragoza, Spain
}

\begin{abstract}
Several graphite-based electrodes are investigated for vanadium flow battery applications. These materials are characterized both as-received and after chemical or electrochemical treatments in order to vary the content of oxygen functional groups on the electrode surface. The surface properties of the samples are investigated by X-ray photoelectron spectroscopy. Electrochemical performance is evaluated by cyclic voltammetry and electrochemical impedance spectroscopy measurements in a three electrode half-cell. The chemical treatment with $\mathrm{HNO}_{3}$ causes a cleaning of the electrode surface from adsorbed oxygen species or labile bonded functional groups in highly graphitic samples. Whereas, carbonaceous materials characterized by smaller graphitic domains or a higher degree of amorphous carbon show an increase of oxygen functional groups upon chemical and electrochemical pre-treatments. In both cases, an increase of oxygen species content on the surface above $5 \%$ causes a decrease of electrochemical performance for the redox battery determined by an increase of ohmic and charge transfer resistance.
\end{abstract}

Key words: Vanadium flow battery, electrochemical activity, carbon nanofiber, carbon felt, rod graphite, carbon paper 


\section{Introduction}

Nowadays, there is a growing interest in redox flow batteries (RFBs) promoted by the significant amount of electric power produced from renewable energy sources [1-3]. In particular, RFBs may become an effective energy storage system where electrical energy is stored as chemical energy to compensate the intermittent behaviour of renewable energy source. This can assure uninterrupted electric power supply [1]. Both in the field of industry and research a lot of attention is paid to continuous optimization of materials and components [4-10]. Several efforts are addressed specifically to vanadium flow batteries (VFBs). This kind of storage system exploits the four oxidation states of vanadium in two reaction compartments. These redox couples play a key role on battery lifetime and allow minimizing the cross-contamination of the two half-cell electrolytes [11]. Concerning this aspect, a fundamental role to prevent the vanadium species permeation is played by the separator between the compartments [12-14]. Ionic exchange membranes (IEM), such as Nafion 117, Daramic, Selemion CMV [15], are the most common utilized separators able to minimize the self-discharge phenomenon [16]. IEM are able to guarantee both a low resistance by assisting the ionic conduction, necessary to complete the circuit, and a good chemical stability. Despite this, the membrane is not $100 \%$ selective for protons with respect to vanadium ions [16]. The crossover of vanadium species through the separator leads towards a self-discharge of the cell. This decreases the current efficiency of the battery. Another critical aspect of the technology is concerning with the electrocatalytic activity and the reversibility of the redox reaction at the positive electrode $\left[\mathrm{VO}^{2+} /\left[\mathrm{VO}_{2}\right]^{+}[17]\right.$. The optimization of these parameters allows increasing the overall efficiency of the battery [18-24]. In order to increase the rate of the specific reactions involved in the redox batteries, several thermal and chemical treatments have been investigated by Brodie, Hummers, Staudenmaier et al. [25-28]. Chemical and thermal treatments are responsible of the surface morphology modifications allowing the formation of oxygen functional groups on the electrode surface [29]. The oxidizing agents as well as the thermal process lead to $\mathrm{CO}$ and/or $\mathrm{CO}_{2}$ evolution or to the occurrence of the carbon functional groups, such as phenolic (C-O), carboxylic or 
carbonyl groups $(\mathrm{C}=\mathrm{O}, \mathrm{C}-\mathrm{O}-\mathrm{C})$ [30]. It is often reported in the literature that the presence of the oxygen functional groups may produce an enhancement of the electrochemical activity of the vanadium ions on the electrode surface favoring the charge transfer at the electrode/electrolyte interface. [31-32]. Moreover, the surface wettability of the electrode increases thanks to the hydrophilicity enhancement due to the oxygen groups presence [30]. Yet, some authors have observed that an increase of the content of oxygen groups can affect negatively the electrochemical performance of a graphite felt electrode due to the increase of the electrical resistivity [33]. The presence of the carbon-oxygen functional groups can also lead to $\mathrm{CO}_{2}$ evolution with an increase of the corrosion rate of the graphite electrode [31]. In this work, several electrode materials and specific surface modification procedures were investigated in order to elucidate the influence of the surface characteristics on the electrochemical performance. The type and content of surface functional groups were determined by using X-ray photoelectron spectroscopy.

\section{Experimental}

Several graphite-based electrodes such as carbon felt, (CF, Freudenberg H2315), carbon paper (CP, Spectracorp 2050), rod graphite (GR, Sigma-Aldrich) and an in-house prepared fishbone carbon nanofibers (CNFs) powder [34] were characterized both as-received and after chemical treatment. A simple and fast chemical method consisting in an acid treatment in $68 \%$ wt. nitric acid $\left(\mathrm{HNO}_{3}\right.$, Aldrich) at $115{ }^{\circ} \mathrm{C}$ for $2 \mathrm{~h}$ was carried out on all samples in order to activate the electrodes. All samples were abundantly washed by bidistilled water and then vacuum dried at $60{ }^{\circ} \mathrm{C}$ for $1 \mathrm{~h}$. Carbon felt was used as support for the electrode based on CNF powders. An appropriate mixture of the CNF powder and 0.5\% Carboxymethylcellulose 0.4\% (CMC, Sigma-Aldrich) was deposited on the carbon felt by a doctor blade method. All the electrochemical tests were carried out by using the same procedure; cyclic voltammetry (CV) and electrochemical impedance spectroscopy (EIS) measurements were carried out in a solution of $0.2 \mathrm{~mol} \mathrm{l}^{-1} \mathrm{VOSO}_{4}\left(97 \%\right.$ wt. $\mathrm{VOSO}_{4} \cdot \mathrm{xH}_{2} \mathrm{O}$ SigmaAldrich) in $2 \mathrm{~mol} \mathrm{l}^{-1} \mathrm{H}_{2} \mathrm{SO}_{4}$ by a three-electrode half-cell. Potential values were measured against a 
saturated calomel $\left(\mathrm{Hg}_{2} / \mathrm{Hg}_{2} \mathrm{Cl}_{2}\right)$ reference electrode whereas Pt was used as counter electrode. The active area was $1.3 \mathrm{~cm}^{2}$ for all the samples. An AUTOLAB FRA equipped Galvanostat/Potentiostat (Metrohm) was used for the electrochemical tests. The reported potential values have been normalized with respect to the standard hydrogen electrode (SHE). Ac-impedance spectra were carried out at potential values of practical interest for application in vanadium flow batteries e.g. $0.24 \mathrm{~V}, 1 \mathrm{~V}, 1.1 \mathrm{~V}$ vs. SHE depending on the specific reversibility of the redox process. For one of these samples, CF, beside the general chemical treatment, a parallel surface modification procedure in single cell was used. A piece of the treated electrode was thereafter characterized in half-cell by the usual procedure. A single cell of $25 \mathrm{~cm}^{2}$, equipped with a Nafion 117 membrane and carbon felt, both as anode and cathode electrode, were used to carry out an accelerated test consisting in an overcharge at $2.5 \mathrm{~V}$ for $2 \mathrm{~h}$ at room temperature. The electrolyte was $0.2 \mathrm{~mol} \cdot \mathrm{l}^{-1} \mathrm{VOSO}_{4}$ in $2 \mathrm{~mol} \cdot \mathrm{l}^{-1}$ $\mathrm{H}_{2} \mathrm{SO}_{4}$ fed in both compartments at a flow rate of $20 \mathrm{ml} \cdot \mathrm{min}^{-1}$. An 857 Fuel Cell Redox Test Station by Scribner Associated Inc. was used for the single cell electrochemical treatment. The surface composition of the electrodes, before and after different treatments, was investigated by X-ray photoelectron spectroscopy (XPS) using a Physical Electronics (PHI) 5800-01 spectrometer. The XPS instrument was equipped with a PHI Multipack library that was used to identify surface species.

\section{Results and discussion}

The electrochemical behaviour of the different graphite-based materials was evaluated, before and after the treatment. The performance of the bare CF electrode was assessed for both the as received sample and after nitric acid treatment by using CV in a three-electrode half-cell. A comparison between these two samples is reported in Fig.1. The chemically treated CF (nitric acid treatment) exhibited a significant decrease in terms of reversibility and electrocatalytic activity for the reaction $\left[\mathrm{VO}^{2+} /\left[\mathrm{VO}_{2}\right]^{+}\right.$. The anodic and cathodic peaks occurred at $1.3 \mathrm{~V}$ and $0.83 \mathrm{~V}$ vs. SHE after the treatment with respect to $1.25 \mathrm{~V}$ and $1 \mathrm{~V}$ vs. SHE before the treatment. The onset potential values of the oxidation reaction were $1.09 \mathrm{~V}$ and $1.14 \mathrm{~V}$ for the CF untreated and CF chemically treated, 
respectively. The lack of a well defined $\mathrm{V}^{2+} / \mathrm{V}^{3+}$ redox behaviour was recorded for both samples. This means that the anodic reaction is not sufficiently reversible on this electrode surface. EIS measurements were carried out on both electrodes at $1.1 \mathrm{~V}$ vs. SHE. This value corresponds to the redox process reaction $[\mathrm{VO}]^{2+} /\left[\mathrm{VO}_{2}\right]^{+}$. A comparison of impedance (Nyquist) plots is reported in Fig. 2. The untreated CF shows both lower series $\left(R_{s}\right)$ and charge transfer resistance $\left(R_{c t}\right)$ with respect the chemically treated sample. A series resistance of $0.23 \mathrm{ohm} \mathrm{cm}^{2}$ and $0.87 \mathrm{ohm} \mathrm{cm}^{2}$ and a charge transfer resistance of $1.6 \mathrm{ohm} \mathrm{cm}^{2}$ vs. $4.2 \mathrm{ohm} \mathrm{cm}^{2}$ were recorded for the CF untreated and CF treated in $\mathrm{HNO}_{3}$, respectively. The higher charge transfer resistance recorded for the latter electrode indicates a slower reaction at the electrode/electrolyte interface. Thus ac-impedance data confirmed the electrochemical performance results. In order to investigate the correlation between the electrochemical properties and the modification of the electrode surface due to the chemical treatment, XPS analyses were conducted on both the electrodes. A direct comparison of O1s and C1s curve fitting for untreated CF and CF treated in nitric acid is shown in Fig. 3. An increase of the oxygen groups percentage due to the chemical treatment was recorded. The total amount of oxygen (\% O1s) on the electrode increased from 4.12 to 8.82 passing from untreated to treated sample. This was corresponding to an increase of the atomic $\mathrm{O} / \mathrm{C}$ ratio from 0.04 to 0.1 . From deconvolution analysis, four carbon species were determined occurring at specific Binding Energy (B.E.) i.e. graphitic carbon (284.4 eV), defects in the carbon felt fibre structure (285 eV), carbonylic species (288 eV), carboxylic species (290.5 eV) (Fig. 3a) [27-28]. The oxygenated groups show much lower intensities than pure carbon species. The C1s profile was similar in the treated sample with an increase of high B.E. oxygenated species (Fig. 3c). The O1s signal shows two oxygen species associated to the previously mentioned functional groups (Fig. 3b-d).

The occurrence of functional groups on the treated CF appeared responsible for both increase of the series and charge transfer resistance recorded by EIS measurements that is confirmed by electrochemical performance decrease. These experimental results were in contrast with some earlier reports [25-32]. In order to investigate more in depth such phenomenon, the same tests were 
conducted on the other graphite-based electrodes in order to verify the effect of the chemical treatment on the electrochemical behaviour. A carbon paper electrode $(\mathrm{CP})$ was subjected to the same procedure of CF. Both electrodes, as-received and treated in nitric acid, were electrochemically tested in a three-electrode half-cell. A comparison of the cyclic voltammetries for the two samples is reported in Fig. 4. Beside the poor reversibility for both bare and treated samples, it is interesting to observe that an opposite behaviour for the electrochemical performance is obtained compared with the CF samples. A significant enhancement of the electrocatalytic activity for the treated CP electrode, both in terms of peak potential separation $\left(\Delta \mathrm{E}_{\mathrm{P}}\right)$ and oxidationreduction peak current $\left(\mathrm{I}_{\mathrm{pa}} / \mathrm{I}_{\mathrm{pc}}\right)$, is evident. The oxidation onset potential was $1.18 \mathrm{~V}$ and $1.11 \mathrm{~V}$ vs. SHE for the CP untreated and treated, respectively. The redox peak potential for the $[\mathrm{VO}]^{2+} /\left[\mathrm{VO}_{2}\right]^{+}$ reaction was $1.37 \mathrm{~V}$ and $0.78 \mathrm{~V}$ vs. SHE for the treated $\mathrm{CP}$. An impedance spectroscopy measurement was carried out at $1.1 \mathrm{~V}$ vs. SHE (Fig. 5). The series resistance value was $0.61 \mathrm{ohm}$ $\mathrm{cm}^{2}$ and $0.87 \mathrm{ohm} \mathrm{cm}^{2}$ for the treated and bare CP, respectively. The smaller semicircle (2.2 ohm $\mathrm{cm}^{2}$ vs. $10.6 \mathrm{ohm} \mathrm{cm}^{2}$ ) for the treated $\mathrm{CP}$ is indicative of a faster reaction rate at the electrode/electrolyte interface. This is consistent with the CV results. XPS analysis revealed a decrease of oxygen species on the treated electrode due to a cleaning effect of nitric acid in this case (Fig. 6). The chemically treated sample showed a much lower oxygen intensity if compared with the untreated sample. The atomic percentage of oxygen decreased from 9.49 to 2.70 for the bare CP and treated CP, respectively. For this sample, the decrease of the functional groups due to the chemical treatment allowed to enhance the electrocatalytic activity of the reaction $[\mathrm{VO}]^{2+} /\left[\mathrm{VO}_{2}\right]^{+}$. The deconvoluted XPS profiles of CP are similar to the CF sample (Fig. 6 a-d).

Fishbone carbon nanofibers (CNF) were investigated in order to evaluate the effect of nitric acid treatment on this material. A CV comparison between bare CNF and chemically treated CNF is shown in Fig. 7. Peak to peak separation and the ratio of the peak current were quite similar for both electrodes. The untreated CNF showed the presence of well defined peaks at $-0.18 \mathrm{~V}$ and $-0.38 \mathrm{~V}$ vs. SHE associated with the couple $\mathrm{V}^{2+} / \mathrm{V}^{3+}$. Whereas the lack of such oxidation-reduction peaks 
was evident for the treated CNF electrode. This indicates that such reaction is irreversible on the chemically treated CNF surface. EIS measurements were carried out at $1 \mathrm{~V}$ and $-0.24 \mathrm{~V}$ vs. SHE (Figs. 8-9). The Nyquist plots showed a semicircle at high frequencies and a linear Warburg type response at low frequencies, indicating that the process $[\mathrm{VO}]^{2+} /\left[\mathrm{VO}_{2}\right]^{+}$is governed by a mixedcontrol of charge transfer and diffusion. Lower series and charge transfer resistance were recorded for the CNF electrode with respect to the chemically treated CNF. Similar evidences are observed in the spectra carried out at $-0.24 \mathrm{~V}$ vs. SHE where the $\mathrm{V}^{2+} / \mathrm{V}^{3+}$ redox couple is involved. XPS analysis was carried out on the bare CNF and treated CNF (Fig. 10 a-d). It was observed that after the chemical treatment, the intensity of O1s peak increased. The percentage of oxygen content changed from $5.03 \%$ to $12.5 \%$. This indicates an increase of the oxygen functional groups due to the oxidation of the electrode surface. For the untreated CNF sample essentially four species are observed like the ether samples (Fig $10 \mathrm{a}-\mathrm{b}$ ). The peak at $287.5 \mathrm{eV}$ in the deconvoluted C1s spectrum is more likely related to other species instead of carbonyl species occurring at $288 \mathrm{eV}$. A fitting with four carbon species was necessary for the treated sample (Fig. 10 c-d). A new peak at $286.3 \mathrm{eV}$ is associated to $\mathrm{C}-\mathrm{OH}$ species which appear in addition to the previously mentioned species [28].

This significant chemical modification caused by the nitric acid treatment, led to a decrease of the electrochemical performance. Electrocatalytic activity decreased as a function of the chemical treatment due to increase of oxygen species content. This result was similar to CF but in contrast with respect to what observed for treated CP. For the latter, a significant increase of the electrocatalytic activity and a reduction of oxygen functional groups on the electrode surface were observed after the treatment. It seems that a large content of oxygen functional groups is not favourable for different carbon electrodes. To better understand this phenomenon, a graphite rod (GR) was investigated. CV and EIS measurements were carried out both on the bare GR and on the nitric acid treated GR. A comparison between these two electrodes is reported in Fig. 11. A slight improvement in terms of the reversibility of the $[\mathrm{VO}]^{2+} /\left[\mathrm{VO}_{2}\right]^{+}$redox reaction was observed after 
the treatment. The oxidation peak of $\mathrm{V}^{2+} / \mathrm{V}^{3+}$ occurred at $-0.2 \mathrm{~V}$ for the treated GR whereas it was absent for the untreated GR. The electrode surface activation for the $\mathrm{V}^{2+} / \mathrm{V}^{3+}$ reaction due to the nitric acid treatment was evident. Fig. 12 shows the Nyquist plots of both electrodes at $1.1 \mathrm{~V}$ vs. SHE. The series resistance was $0.73 \mathrm{ohm} \mathrm{cm}^{2}$ and $1.1 \mathrm{ohm} \mathrm{cm}^{2}$ for the untreated and treated GR, respectively. Moreover, the latter shows a smaller semicircle indicative of a faster reaction at the electrode/electrolyte interface. A series resistance value of about $0.72 \mathrm{ohm} \mathrm{cm}^{2}$ at $-0.24 \mathrm{~V}$ vs. SHE is observed (Fig. 13). XPS analysis was carried out both on untreated and treated GR. A decrease of the oxygen percentage after the chemical treatment from $8.61 \%$ to $3.63 \%$ (Fig. 14) was recorded. This behaviour appears similar to the CP sample showing that removal of oxygen species from the surface of electrodes with highly graphitic characteristics allows improving the electrochemical performance. Deconvoluted C1s and O1s species for the graphite rod both before and after treatment were essentially similar to the first two samples.

A decrease of the electrical conduction on the electrode surface is correlated to the presence of specific oxygen groups, whereas oxygen groups improve wettability. The electrochemical activity of the electrode is influenced by both aspects. Moreover, oxidation phenomena can lead to performance degradation. In Tab 1 the oxygen content for all the analyzed samples, before and after chemical treatment, is reported. It seems that an oxygen percentage above a defined value e.g. $5 \%$ causes a decrease of the electrochemical performance. In order to further explore the correlation between the surface modifications and the electrocatalytic activity, an accelerated test was carried out by using a single cell equipped with CF electrodes and a Nafion 117 membrane as separator between two compartments. A potential of $2.5 \mathrm{~V}$ was applied for $2 \mathrm{~h}$. A large gas evolution was evident at the anode side indicating that a corrosion process occurs on the surface. A small piece of the anode was cut from the membrane-electrode assembly and tested in a three electrode half-cell following the usual procedure (Fig. 15). A dramatic decrease of the electrocatalytic activity was observed after such an accelerated test if compared to the bare CF. Peak to peak separation $\left(\Delta \mathrm{E}_{\mathrm{P}}\right)$ increased from 0.3 to about $1 \mathrm{~V}$ from the bare to the electrochemically treated CF, respectively. EIS 
analysis confirmed a significant increase both in terms of series and charge transfer resistance for the CF subjected to the accelerated test (Fig. 16). $\mathrm{R}_{\mathrm{s}}$ values increased from $0.28 \mathrm{ohm} \mathrm{cm}^{2}$ to 1.3 ohm $\mathrm{cm}^{2}$ while the $\mathrm{R}_{\mathrm{ct}}$ values changed from 1.5 up to $10 \mathrm{ohm} \mathrm{cm}^{2}$ indicating the drastic deterioration of the electrode/electrolyte interface for the $[\mathrm{VO}]^{2+} /\left[\mathrm{VO}_{2}\right]^{+}$redox process. XPS measurements were carried out on the electrochemically treated CF in order to investigate the surface properties after the corrosion test (Fig. 3e-f). The results showed a severe increase of the oxygen groups on the electrode surface as indicative of a strong oxidation process. This is in accordance with the high series resistance value recorded by EIS measurement. The oxygen percentage increased from $4.12 \%$ to $22.83 \%$ with a consequent increase of the atomic ratio O/C from 0.05 to 0.3 . The $\mathrm{O} 1 \mathrm{~s}$ peak at $537.4 \mathrm{eV}$ is attributed to the epoxy groups in the Nafion ionomer used in this specific single cell treatment that was in contact with the electrode.

C1s spectra of the sample subjected to the electrochemical treatment showed large signal at the peak at high B.E. in the C1s spectrum associated to oxygenated species. The O1s showed the occurrence of two set of peaks, one at low B.E. associated to oxygenated carbon functional groups and one at high B.E. deriving from the oxygen present in the sulphonic groups and ether species in the Nafion ionomer used in the single cell experiment.

The results obtained for the electrochemically treated CF sample corroborated the previous evidence for the chemically treated sample i.e. a large occurrence of surface oxygen groups and high oxygen content on the surface will negatively affect the redox process in vanadium-based redox batteries. Whereas, we do not exclude that a moderate content (4-5\%) may be beneficial for such reactions. This would suggest that a proper ratio between graphitic basal phases and oxygenated catalytic sites may provide a good compromise resulting in a lower overall polarization resistance thus accelerating the redox process. To clarify why in some samples the chemical treatment causes a decrease of oxygen species whereas in other samples an opposite evidence is observed, we have tried to correlate these effects with the graphitic character of such materials [35]. In Fig. $17 \mathrm{X}$-ray diffraction patterns comparison among untreated samples is reported. A larger 
graphitic character were evident for CP and GR with respect the CF and CNF samples as indicated by a sharper $C$ (002) reflection of the hexagonal crystal structure and a shift to lower Bragg angles (Tab. 1). The latter is associated to the shorter distance at the graphitic basal phase whereas the first parameter gives evidence of graphitic domain with larger size. In other words, we can affirm that CF and CNF samples contain a larger fraction of amorphous carbon that can be transformed into functional groups upon a chemical treatment. Whereas, the samples characterized by a larger degree of graphitic character (CP and GR) just loose labile oxygen species during the chemical treatment as in a cleaning procedure. It appears evident from the above results that an increase of oxygen content is not favourable for the reaction electro-kinetics. However, since there are several evidences in the literature that a suitable oxygen content may promote the reaction, we have tried to get more insights into the aspect by plotting the peak current related to the $\mathrm{VO}^{2+} / \mathrm{VO}_{2}^{+}$oxidation process as a function of the surface oxygen content in the sample (Fig. 18). A volcano shaped curve is obtained with a maximum centered at about a $4 \%$ atomic content of oxygen on the electrode surface. However, the large scattering in the data also suggest that other factor such as surface area contribute substantially in determining the electrochemical performance.

\section{Conclusion}

Several graphite-based electrodes were investigated in order to assess the electrochemical performance as a function of physico-chemical properties and modifications induced by chemical and electrochemical treatments. Carbon felt and carbon nanofiber samples characterized by a lower degree of graphitization gave rise to a decrease of the electrocatalytic activity after a chemical treatment causing an increase of the oxygen functional groups on the electrode surface. On the contrary, graphite rod and carbon paper electrodes characterized by a larger graphitic character showed an increase of the reversibility for the $[\mathrm{VO}]^{2+} /\left[\mathrm{VO}_{2}\right]^{+}$redox reaction due to the chemical treatment that caused a cleaning of most of the oxygen species from the surface. CF subjected to overpotential at $2.5 \mathrm{~V}$ for $2 \mathrm{~h}$ in single cell configuration, showed a strong increase of oxygen 
species, up to $22 \%$ and a corresponding dramatic decrease of electrochemical performance with a drastic increase of the series and charge transfer resistance. An oxygen species content of about 4-5 \% provides good electrochemical performance and an appropriate electrical conduction. Higher amount of oxygen functional groups lead to an increase of the ohmic and charge transfer resistance then to a decrease of the electrochemical performance.

\section{Acknowledge}

Authors from CNR-ITAE acknowledge the financial support from "Ministero dello Sviluppo Economico - Accordo di Programma MSE-CNR per la Ricerca del Sistema elettrico Nazionale”. 
Reference

[1] Joerissen L, Garche J, Fabjan C, Tomazic G (2004) J Power Sources 127, 98-104.

[2] Ponce de Leon C, Frias-Ferrer A, Gonzalez-Garcia J, Szanto D, Walsh FC (2006) J Power Sources 160, 716-732.

[3] Fabjan C, Garche J, Harrer B, Jorissen L, Kolbeck C, Philippi F, Tomazic G, Wagner F (2001) Electrochim Acta 47, 825-831.

[4] Y.M. Zhang, Q.M. Huang, W.S. Li, H.Y. Peng, S.J. Hu, J. Inorg. Mater. 22 (2007) 10511055.

[5] G.J.W. Radford, J. Cox, R.G.A. Wills, F.C. Walsh, J. Power Sources 185 (2008) 1499-1504.

[6] B. Sun, M. Skyllas-Kazacos, Electrochim. Acta 37 (1992) 37.

[7] F.Q. Xue, Y.L. Wang, W.H. Wang, X.D. Wang, Electrochim. Acta 53 (2008) 6636-6642.

[8] B. Fang, S. Iwasa, Y. Wei, T. Arai, M. Kumagai, Electrochim. Acta 47 (2002) 3971-3976.

[9] W.H. Wang, X.D. Wang, Electrochim. Acta 52 (2007) 6755-6762.

[10] Y.Y. Shao, M. Engelhard, Y.H. Lin, Electrochem. Commun. 11 (2009) 2064-2067.

[11] Y. Shaoa, X. Wang, M. Engelharda, C. Wanga, S. Daib, J. Liua, Z. Yanga, Y. Lina, J. Power Sources 195 (2010) 4375-4379.

[12] T. Sukkar, M. Skyllas-Kazacos, J. Appl. Electrochem. 34 (2004) 137-145.

[13] T. Sukkar, M. Skyllas-Kazacos, J.of Membrane Science 222 (2003) 249-264.

[14] T. Mohammadi, S.C. Chieng, M. Skyllas Kazacos, J.of Membrane Science 133 (1997) 151159.

[15] M. Skyllas Kazacos, M-H. Chakrabarti, S.A. Hajimolana, F.S. Mjalli and M. Saleem, J. of the Electrochem. Society, 158 (8) R55-R79 (2011).

[16] D. Chen, S. Wang, M. Xiao, Y. Meng, Journal of Power sources 195 (2010) 2089-2095.

[17]. Rychick M, Skyllas-Kazacos M., J Power Sources 19 (1987), pp. 45-54.

[18] J.A. Trainham, J. Newman, Electrochim. Acta 26 (1981) 455.

[19] F. Su, X.S. Zhao, Y. Wang, J.Y. Lee, Micropor. Mesopor. Mater. 98 (2007) 323. 
[20] H.Q. Zhu, Y.M. Zhang, L. Yue, W.S. Li, G.L. Li, D. Shu, H.Y. Chen, J. Power Sources 184 (2008) 637.

[21] Q.S. Song, G.K. Aravindaraj, H. Sultana, S.L.I. Chan, Electrochim. Acta 53 (2007) 1890.

[22] H. Trotter, R. Phillips, B. Ni, Y. Hu, S.B. Sinnott, P.T. Mikulski, J.A. Harrison, J. Nanosci. Nanotechnol. 5 (2005) 536.

[23] V. Haddadi-Asl, M. Kazacos, M. Skyllas-Kazacos, J. Appl. Polym. Sci. 57 (1995) 1455.

[24] H.Q. Zhu, Y.M. Zhang, L. Yue, W.S. Li, G.L. Li, D. Shu, H.Y. Chen, J. Power Sources 184 (2008) 637-640.

[25] B. Sun, M. Skyllas-Kazacos, Electrochemical Acta, 37 (1992), 1253-1260.

[26] B. Sun, M. Skyllas-Kazacos, Electrochemical Acta, 37 (1992), 2459-2465.

[27] L.Yue, W. Li, F. Sun, L. Zhao, L. Xing, Carbon 48 (2010) 3079.

[28] P. Han, H. Wang, Z. Liu, X. Chen, W. Ma, J. Yao, . Zhu, G. Cui, Carbon 49 (2011) 693-700.

[29] W.H. Wang, X.D. Wang, Electrochim. Acta 52 (2007) 6755-6762.

[30] K. J. Kim, Y.-J. Kim, J.-H Kim, M.-S. Park, Materials Chemistry and Physics 131 (2011) 547-553.

[31] S. Zhong, C. Padeste, M. Kazacos, M. Skyllas- Kazacos, J. Power Sources 45 (1993) 29.

[32] W. Li, J. Liu, C. Yan, Electrochimica Acta 56 (2011) 5290-5294.

[33] F. Mohammadi, P. Timbrell S. Zhong C. Padeste, M. Slyllas-Kazacos, J. Power Sources 52 (1994) 61-68.

[34] D. Sebastián, I. Suelves, R. Moliner, M.J. Lázaro, Carbon 48 (2010) 4421- 4431.

[35] V.B. Fenelonov, A. Yu. Derevyankin, L.G. Okkel, L.B. Avdeeva, V.I. Zaikovskii, E. M. Moroz, A. N. Salanov, N. A. Rudina, V. A. Likholobov, Sh. K. Shaikhutdinov, Carbon 35 (1997) 1129-1140. 


\section{Captions}

Figure 1: Cyclic voltammograms of untreated carbon felt and treated carbon felt at a scan rate of 30 $\mathrm{mV} \mathrm{sec}^{-1} ; 0.2 \mathrm{M} \mathrm{VOSO}_{4}+2 \mathrm{M} \mathrm{H}_{2} \mathrm{SO}_{4}$

Figure 2: Nyquist plots comparison between untreated carbon felt and treated carbon felt at $1.1 \mathrm{~V}$

Figure 3: XPS C1s and O1s peaks of untreated carbon felt (a-b), treated carbon felt (c-d) and electrochemically treated carbon felt (e-f)

Figure 4: Cyclic voltammograms of untreated carbon paper and treated carbon paper at a scan rate of $30 \mathrm{mV} \mathrm{sec}{ }^{-1} ; 0.2 \mathrm{MVOSO}_{4}+2 \mathrm{M} \mathrm{H}_{2} \mathrm{SO}_{4}$

Figure 5: Nyquist plots comparison between untreated carbon paper and treated carbon paper at 1.1 V

Figure 6: XPS C1s and O1s peaks of untreated carbon paper (a-b) and treated carbon paper (c-d)

Figure 7: Cyclic voltammograms of untreated Fishbone Carbon Nanofibers and treated Fishbone Carbon Nanofibers at a scan rate of $30 \mathrm{mV} \mathrm{sec}^{-1} ; 0.2 \mathrm{M} \mathrm{VOSO}_{4}+2 \mathrm{M} \mathrm{H}_{2} \mathrm{SO}_{4}$

Figure 8: Nyquist plots comparison between untreated Fishbone Carbon Nanofibers and treated Fishbone Carbon Nanofibers at $1 \mathrm{~V}$

Figure 9: Nyquist plots comparison between untreated Fishbone Carbon Nanofibers and treated Fishbone Carbon Nanofibers at $-0.24 \mathrm{~V}$

Figure 10: XPS C1s and O1s peaks of untreated Fishbone Carbon Nanofibers (a-b) and treated Fishbone Carbon Nanofibers (c-d)

Figure 11: Cyclic voltammograms of untreated graphite rod and treated graphite rod at a scan rate of $30 \mathrm{mV} \mathrm{sec}^{-1} ; 0.2 \mathrm{M} \mathrm{VOSO}_{4}+2 \mathrm{M} \mathrm{H}_{2} \mathrm{SO}_{4}$

Figure 12: Nyquist plots comparison between graphite rod and treated graphite rod at $1.1 \mathrm{~V}$

Figure 13: Nyquist plots comparison between graphite rod and treated graphite rod at $-0.24 \mathrm{~V}$

Figure 14: XPS C1s and O1s peaks of untreated graphite rod (a-b) and treated graphite rod (c-d)

Figure 15: Cyclic voltammograms of carbon felt and post mortem carbon felt at a scan rate of 30 $\mathrm{mV} \mathrm{sec}^{-1} ; 0.2 \mathrm{M} \mathrm{VOSO}_{4}+2 \mathrm{M} \mathrm{H}_{2} \mathrm{SO}_{4}$ 
Figure 16: Nyquist plots comparison between carbon felt and post mortem carbon felt at $1.1 \mathrm{~V}$

Figure 17: XRD diffraction patterns comparison among untreated samples

Figure 18: Peak current for $\mathrm{VO}^{2+} / \mathrm{VO}_{2}{ }^{+}$oxidation as a function of the oxygen content on the electrode surface. 


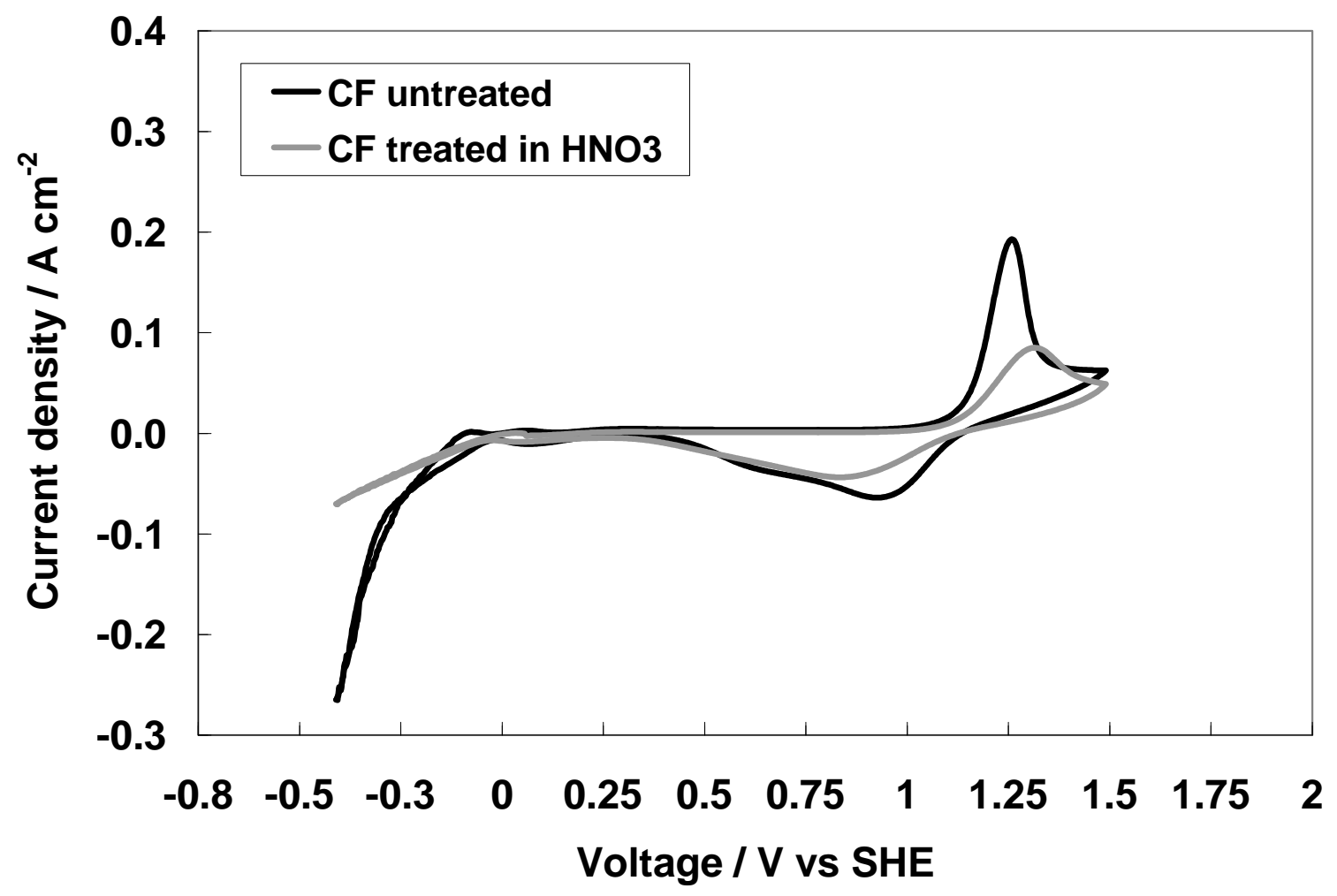

FIG. 1 


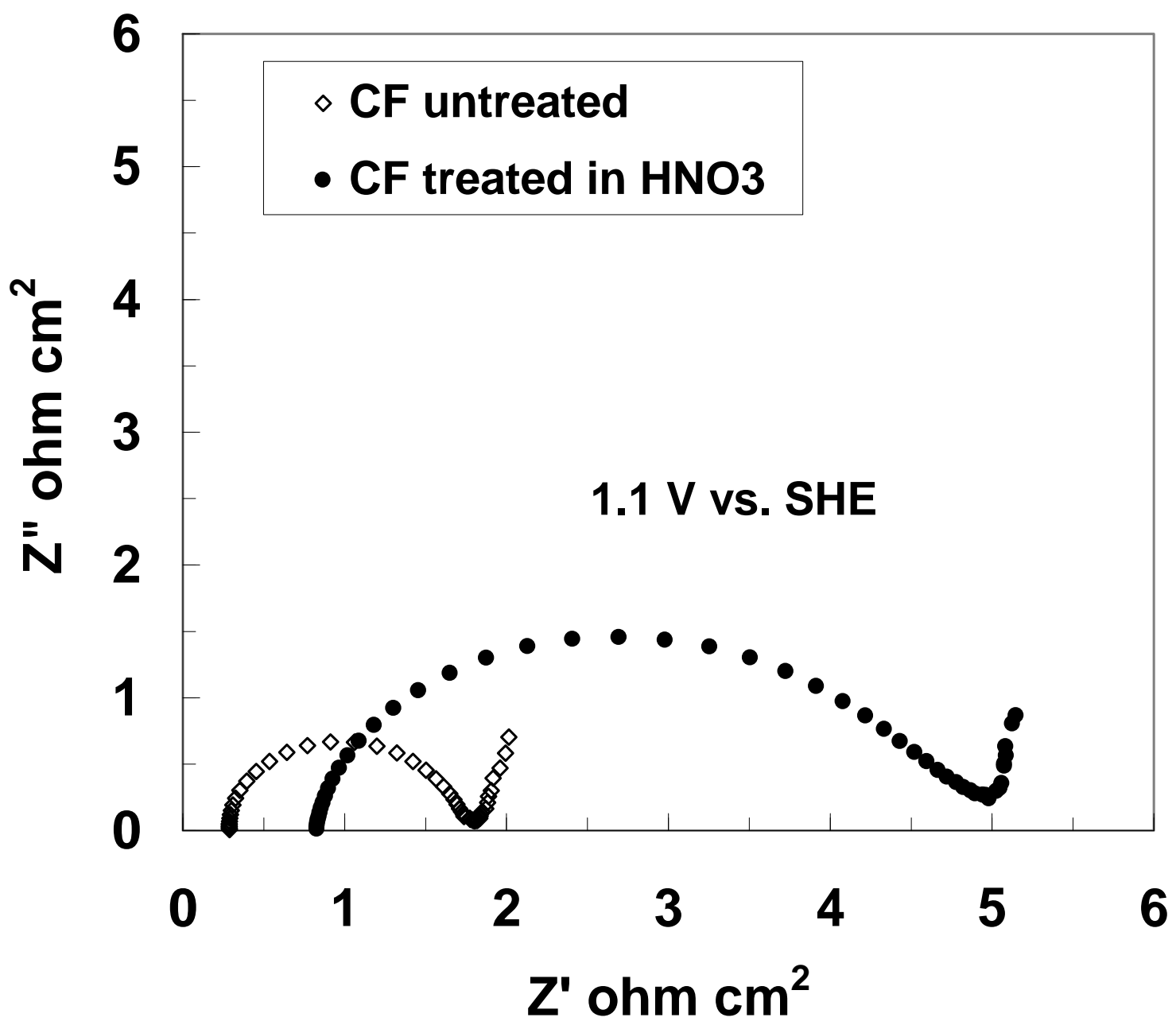

FIG 2 

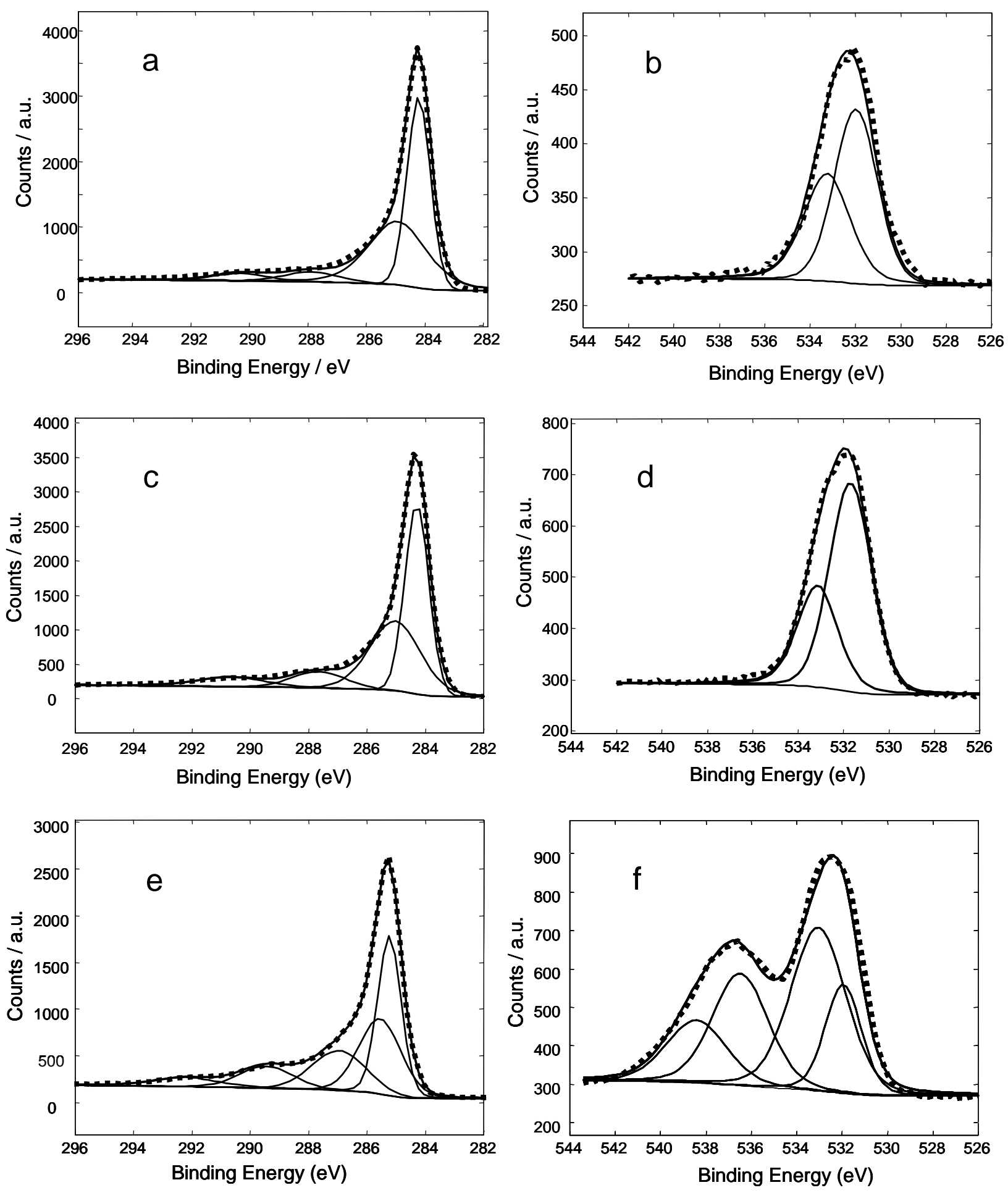

FIG. 3 


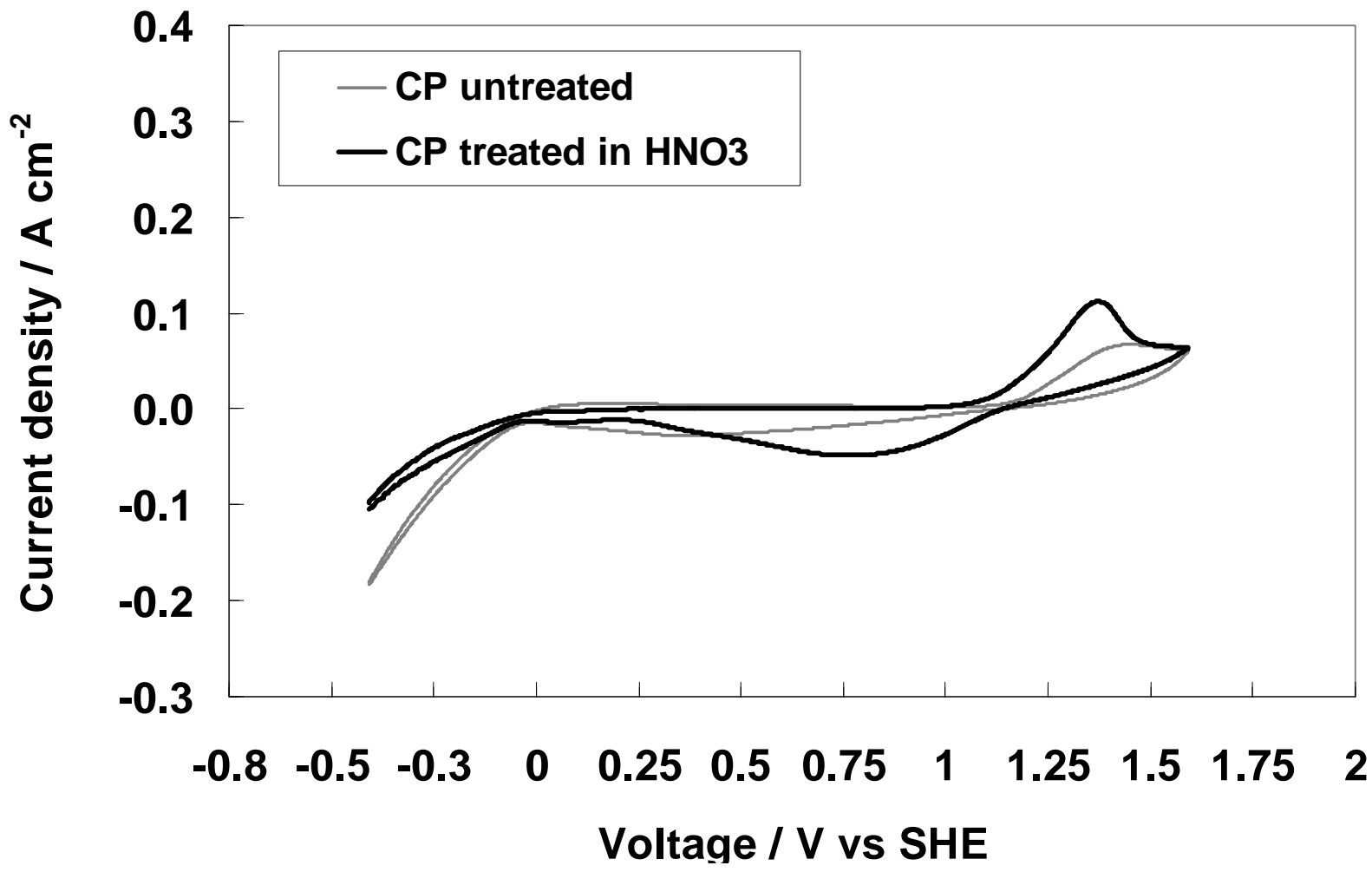

FIG. 4 


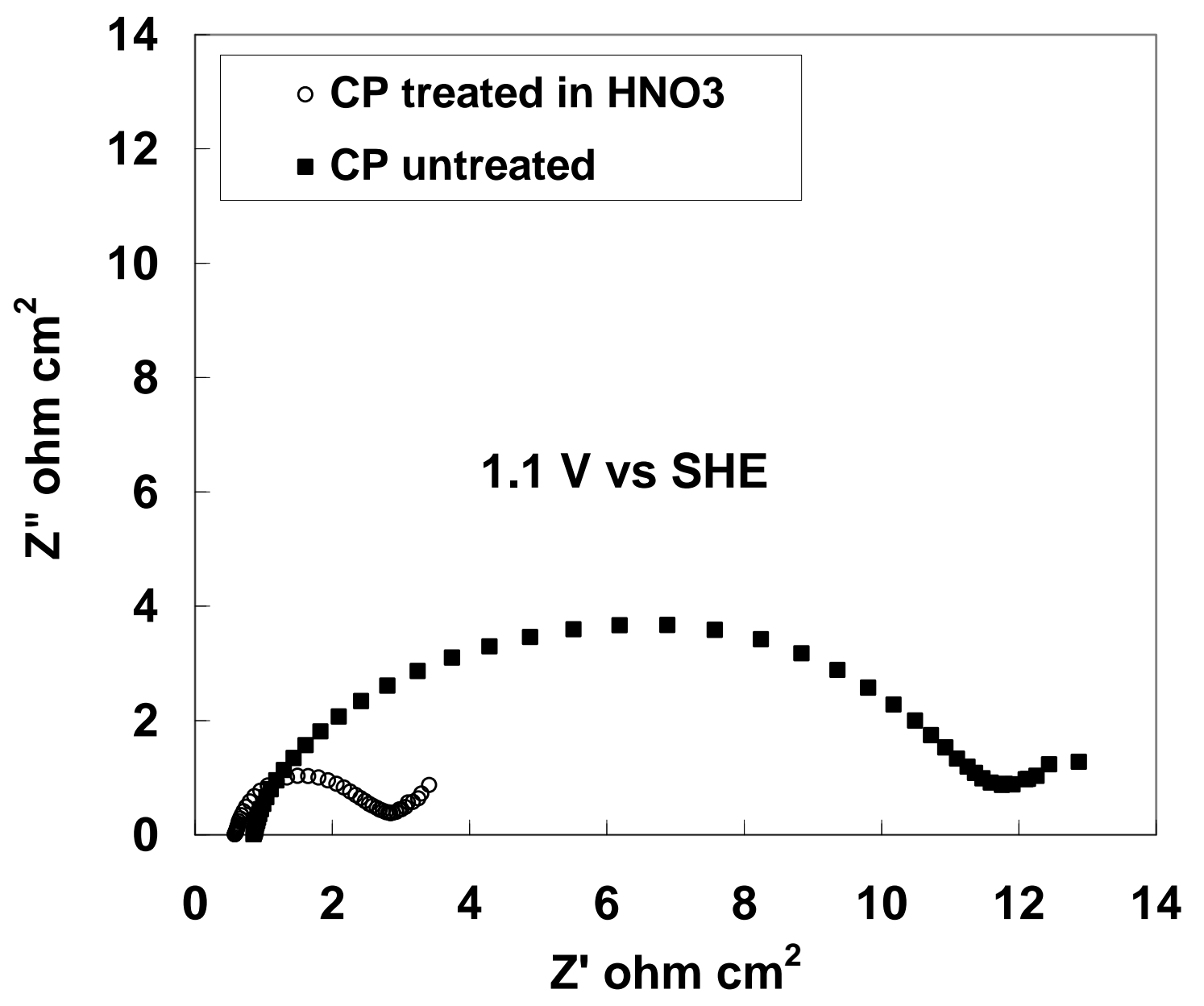

FIG. 5 

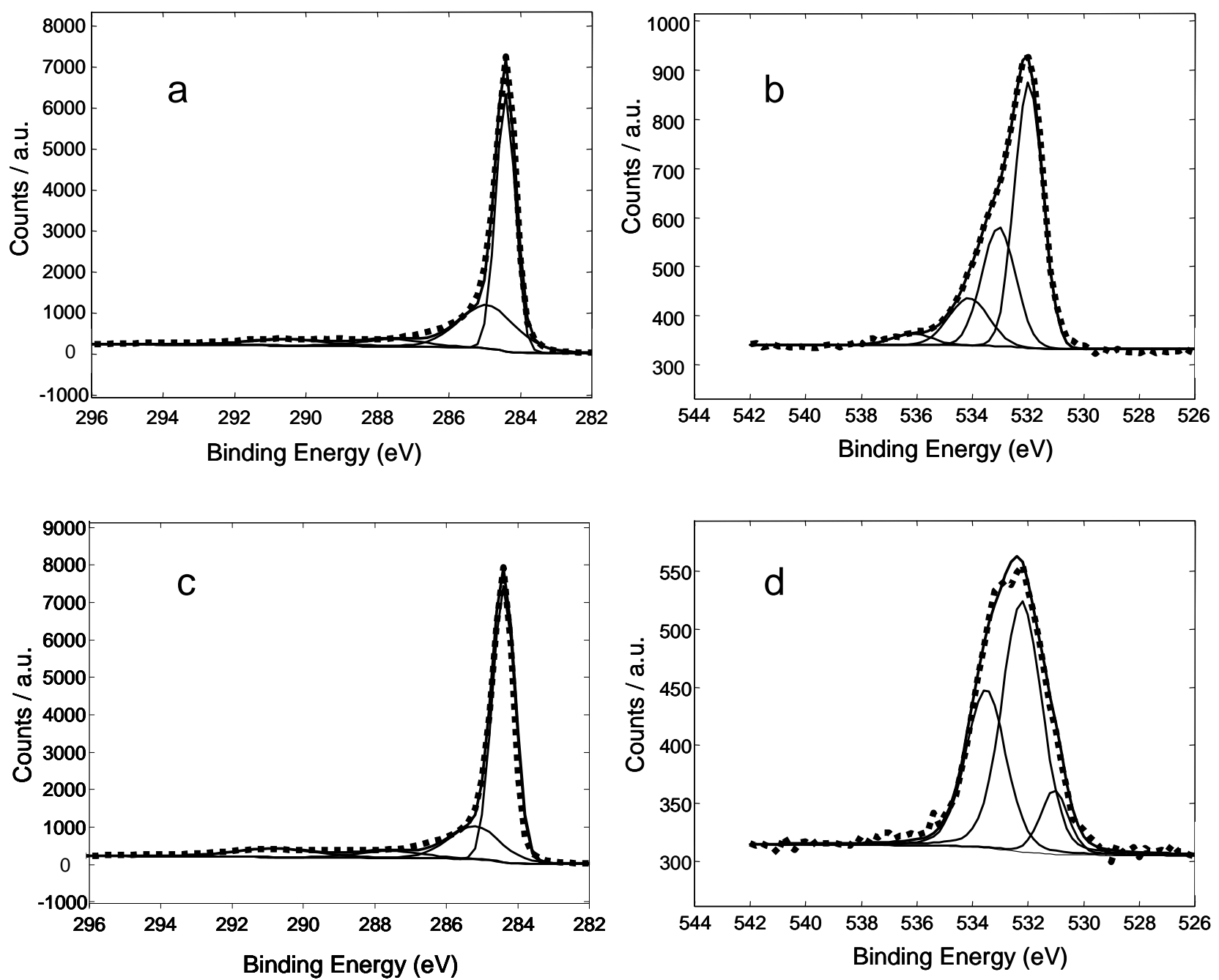

FIG. 6 


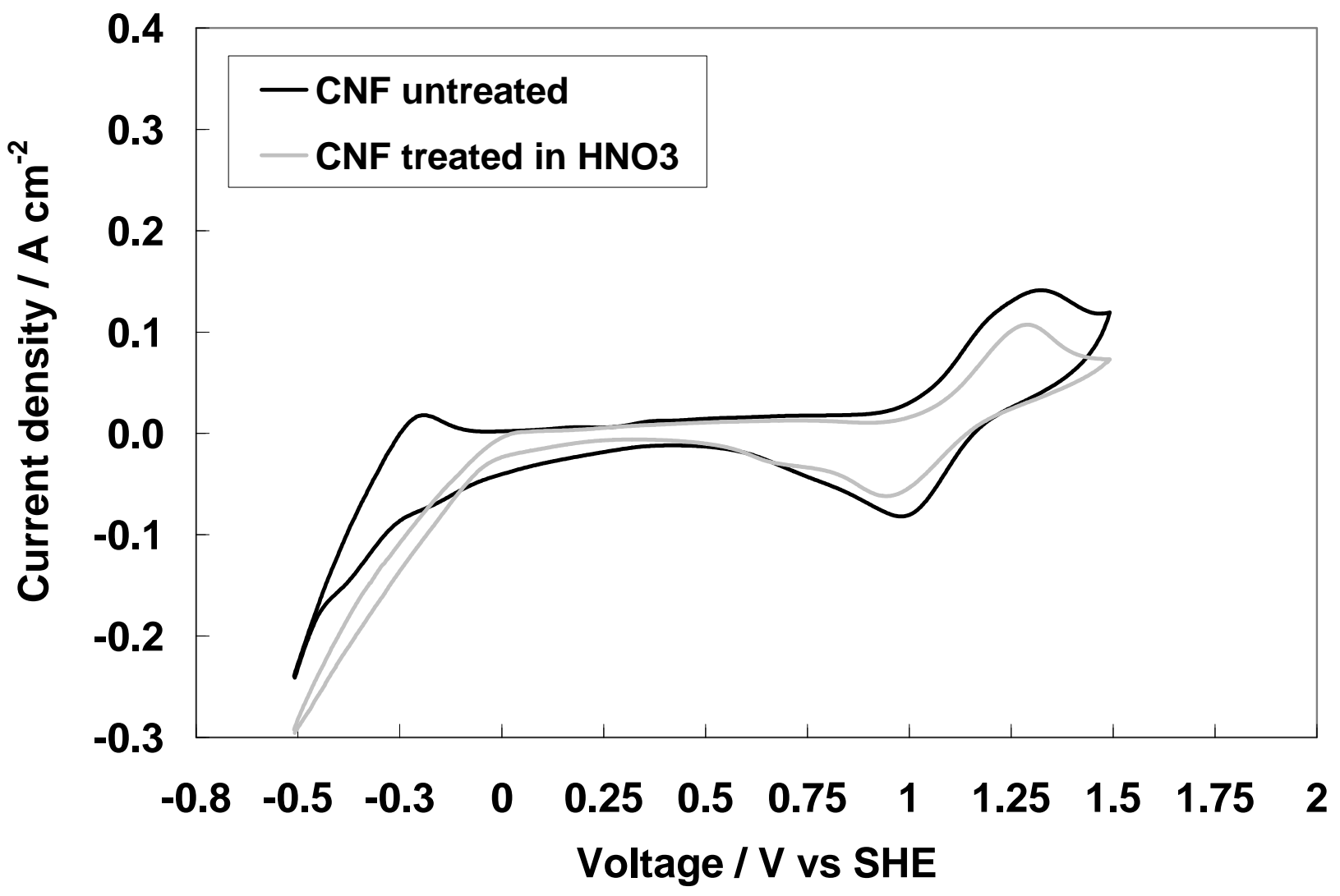

FIG. 7 


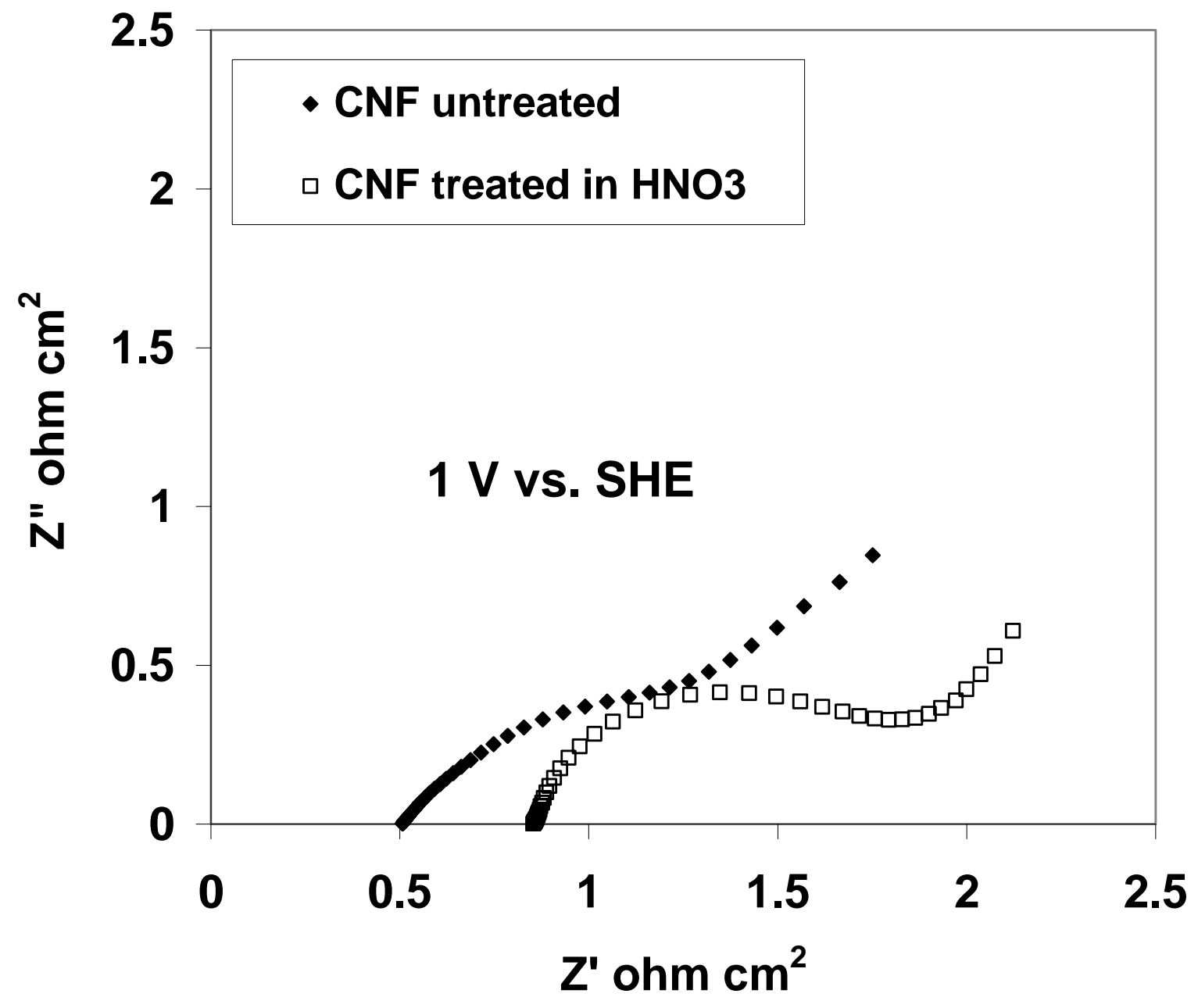

FIG. 8 


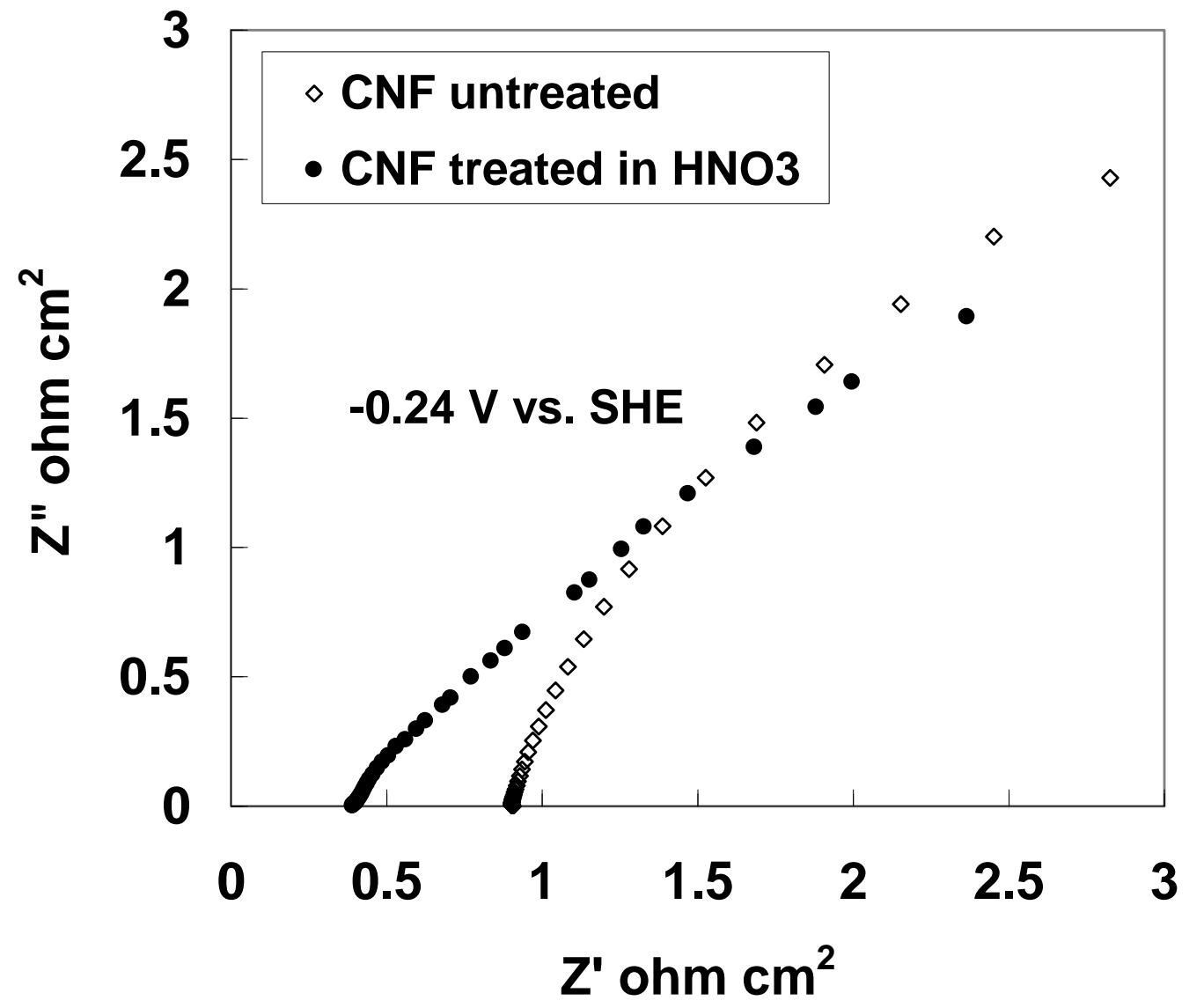

FIG. 9 

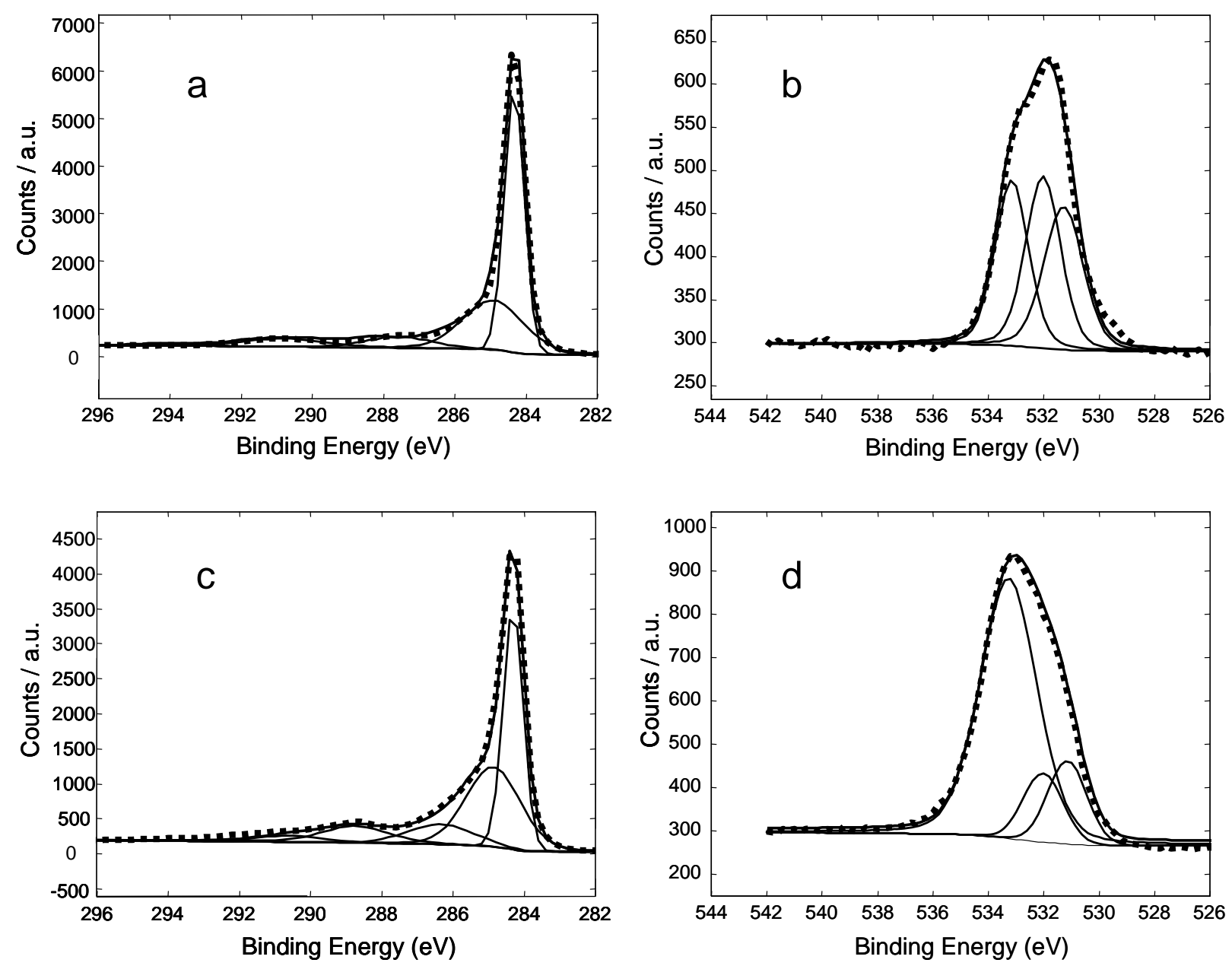

FIG. 10 


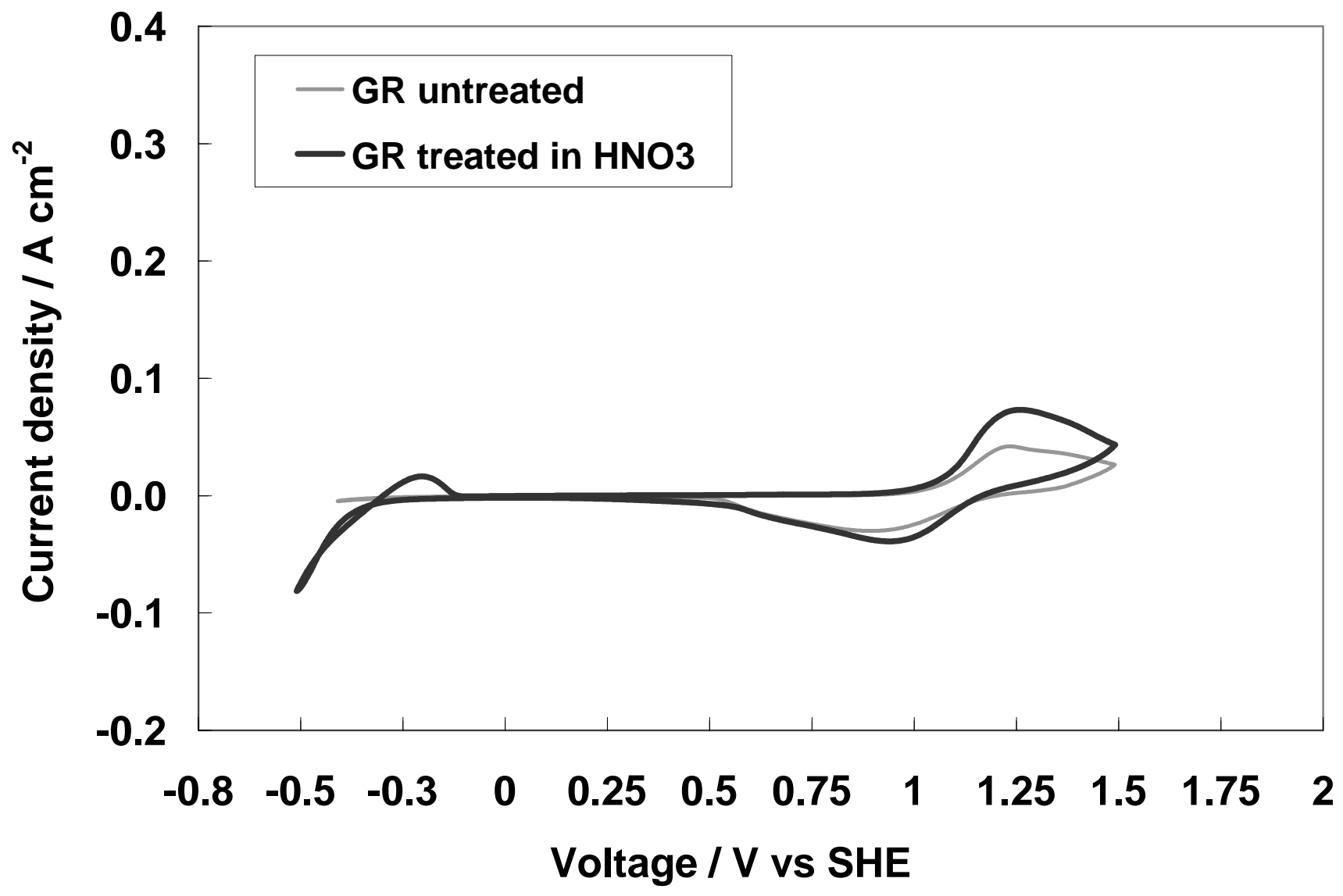

FIG. 11 


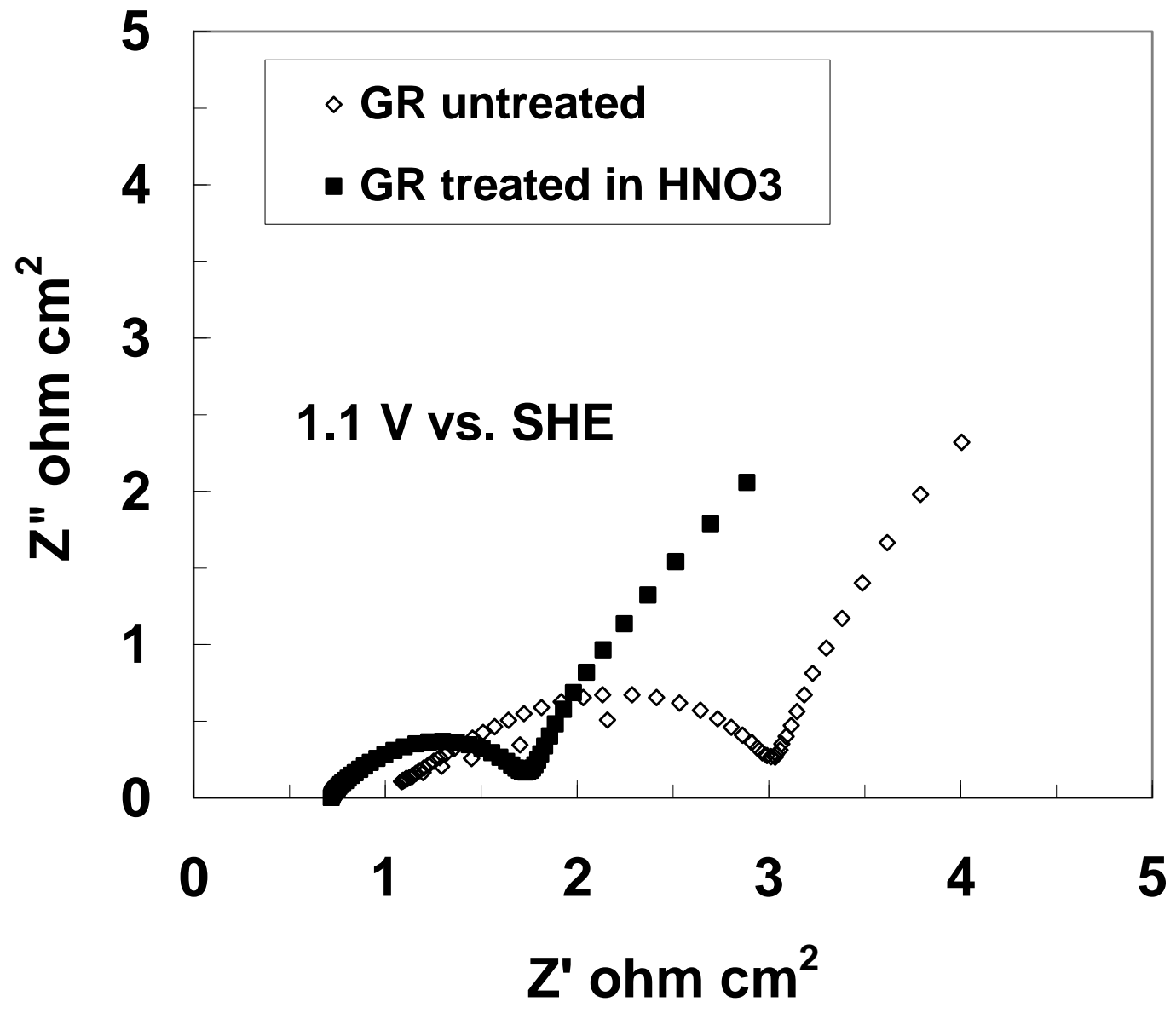

FIG. 12 


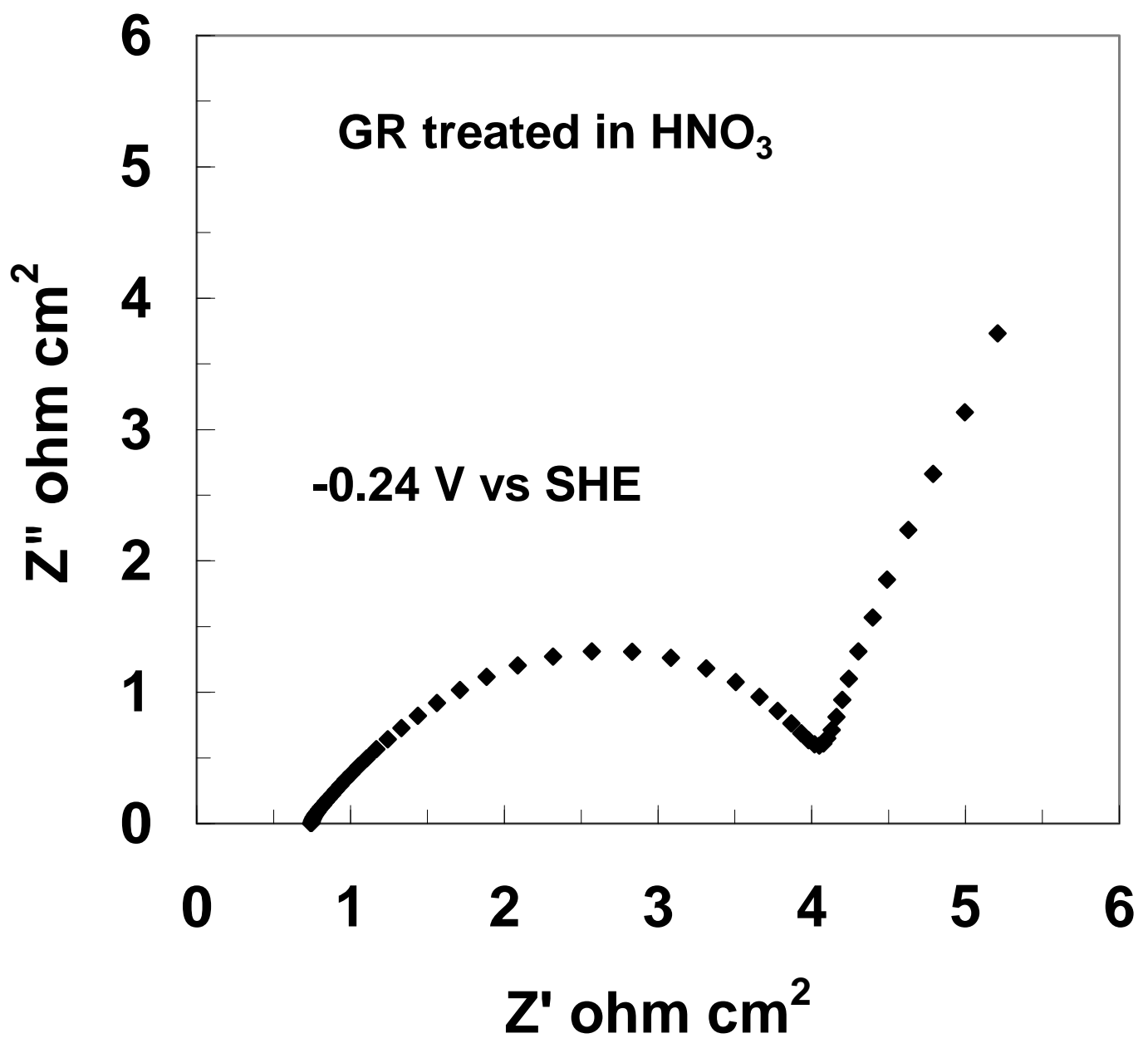

FIG. 13 

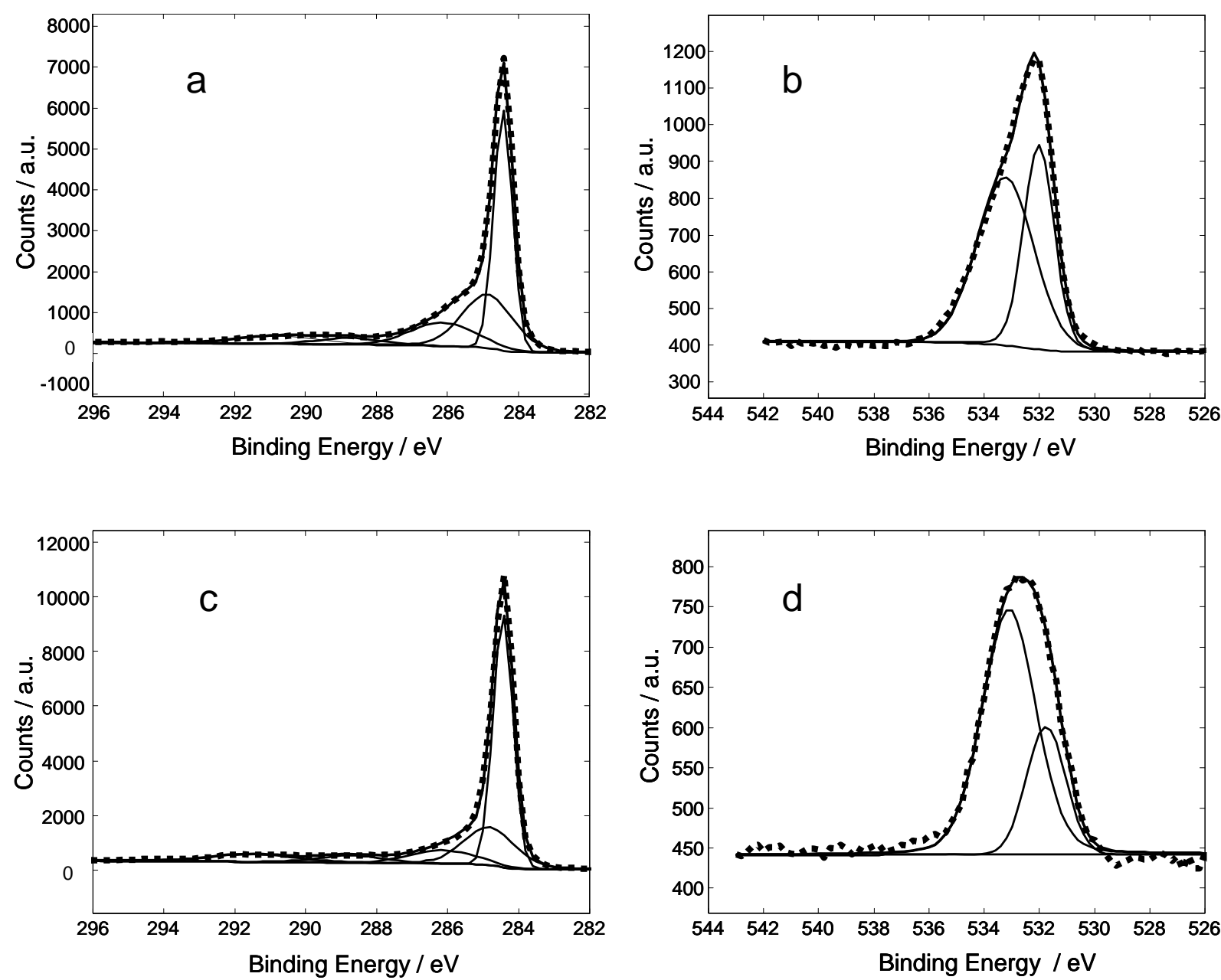

FIG. 14 


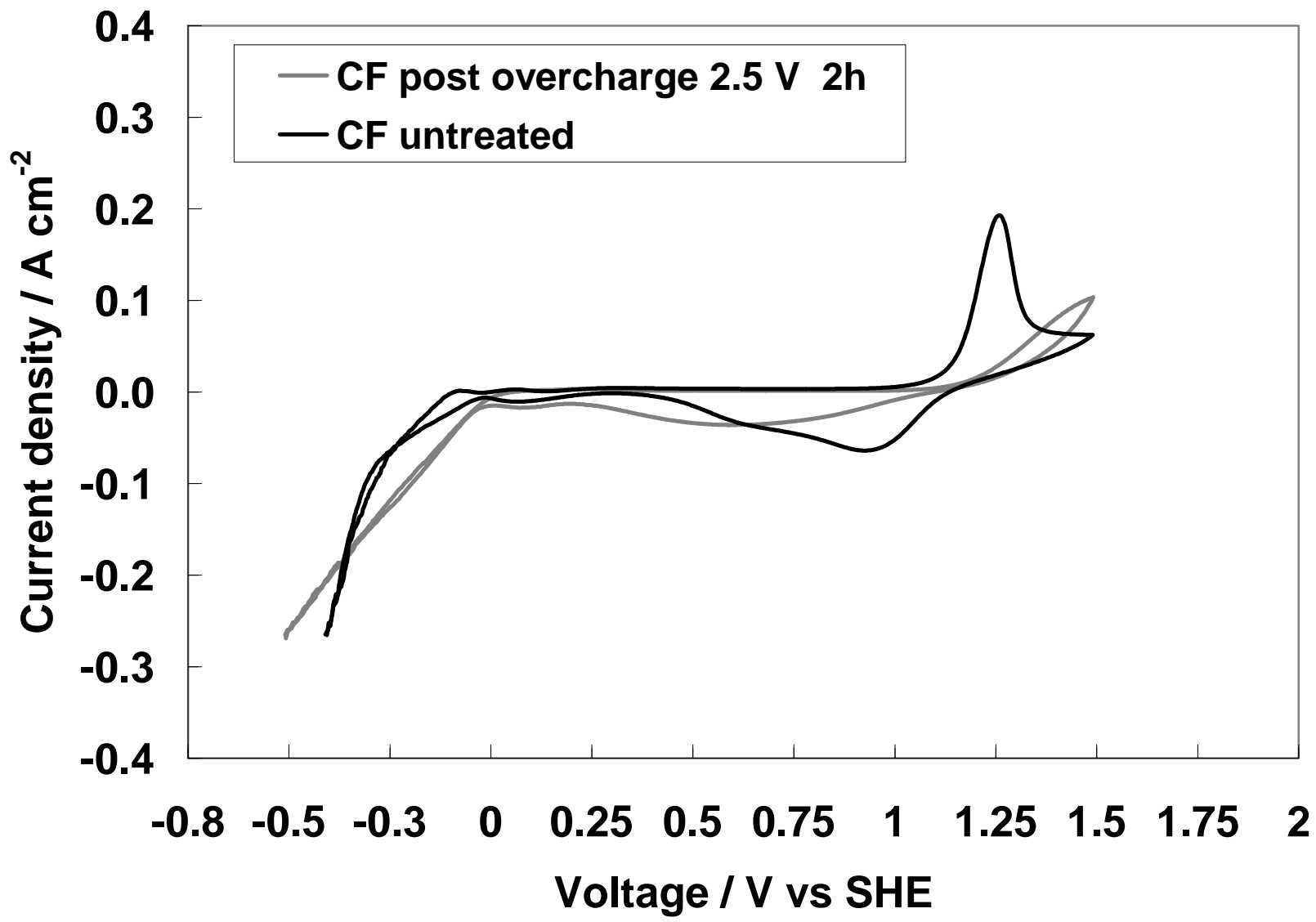

FIG. 15 


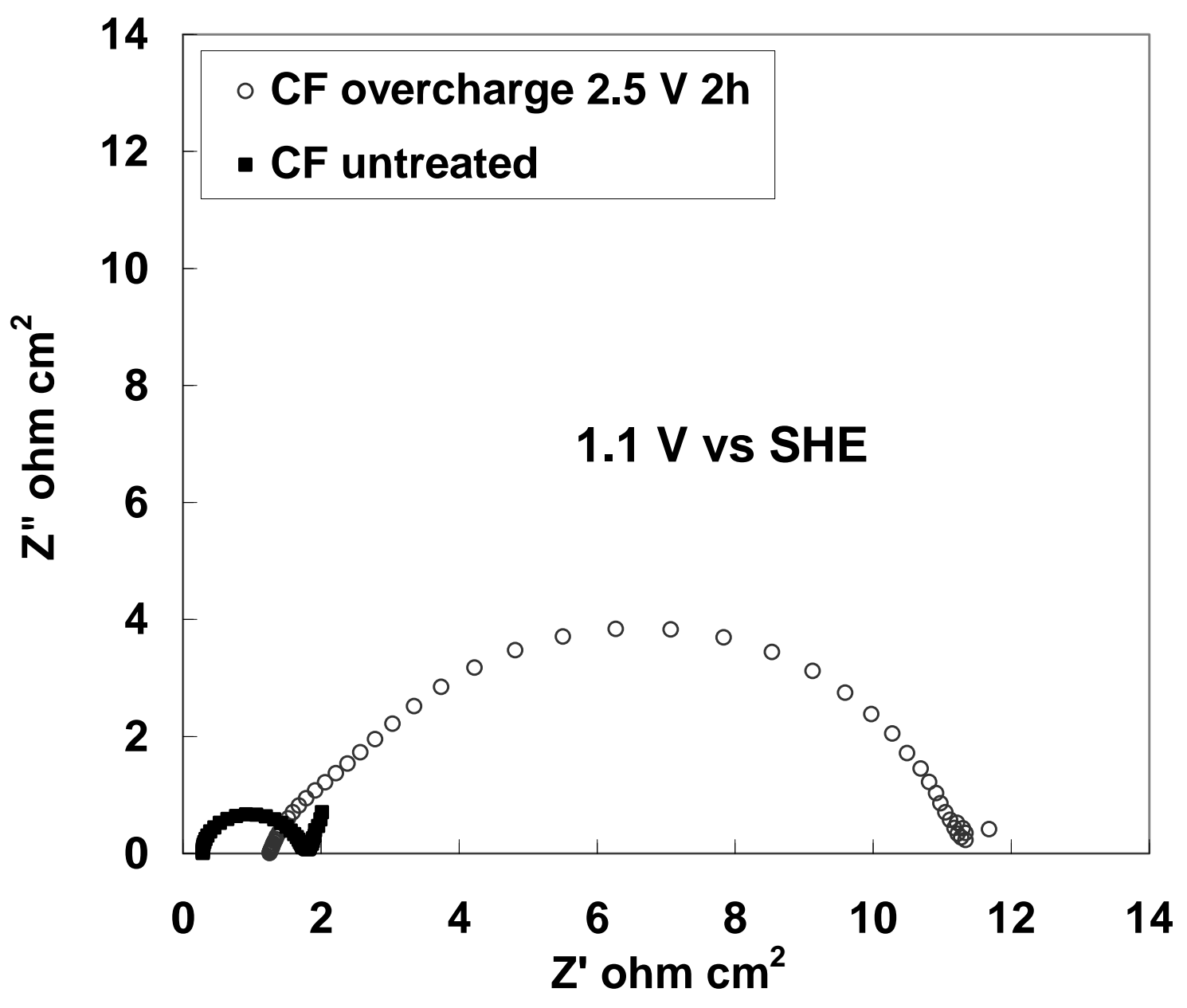

FIG. 16 


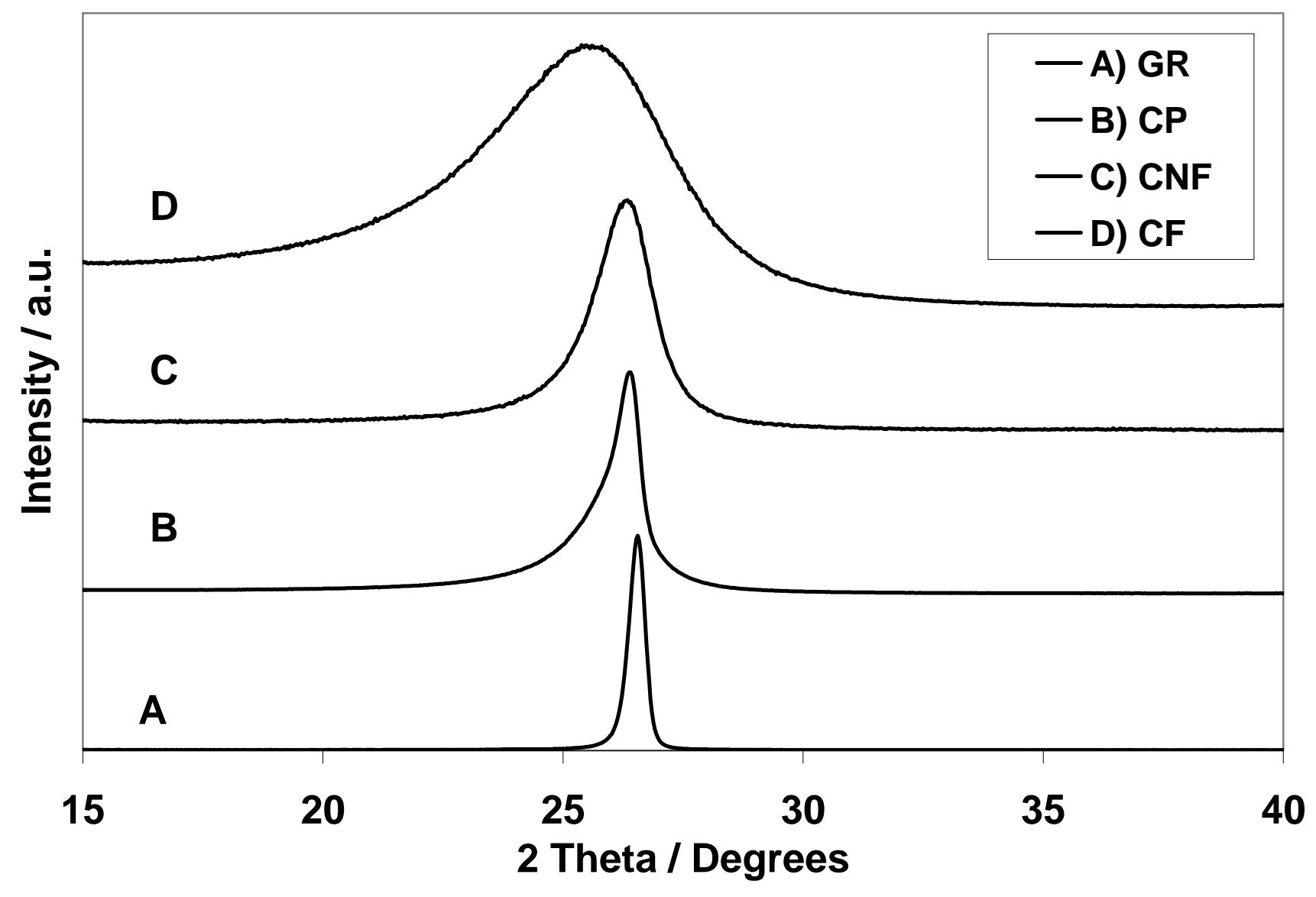

FIG. 17 


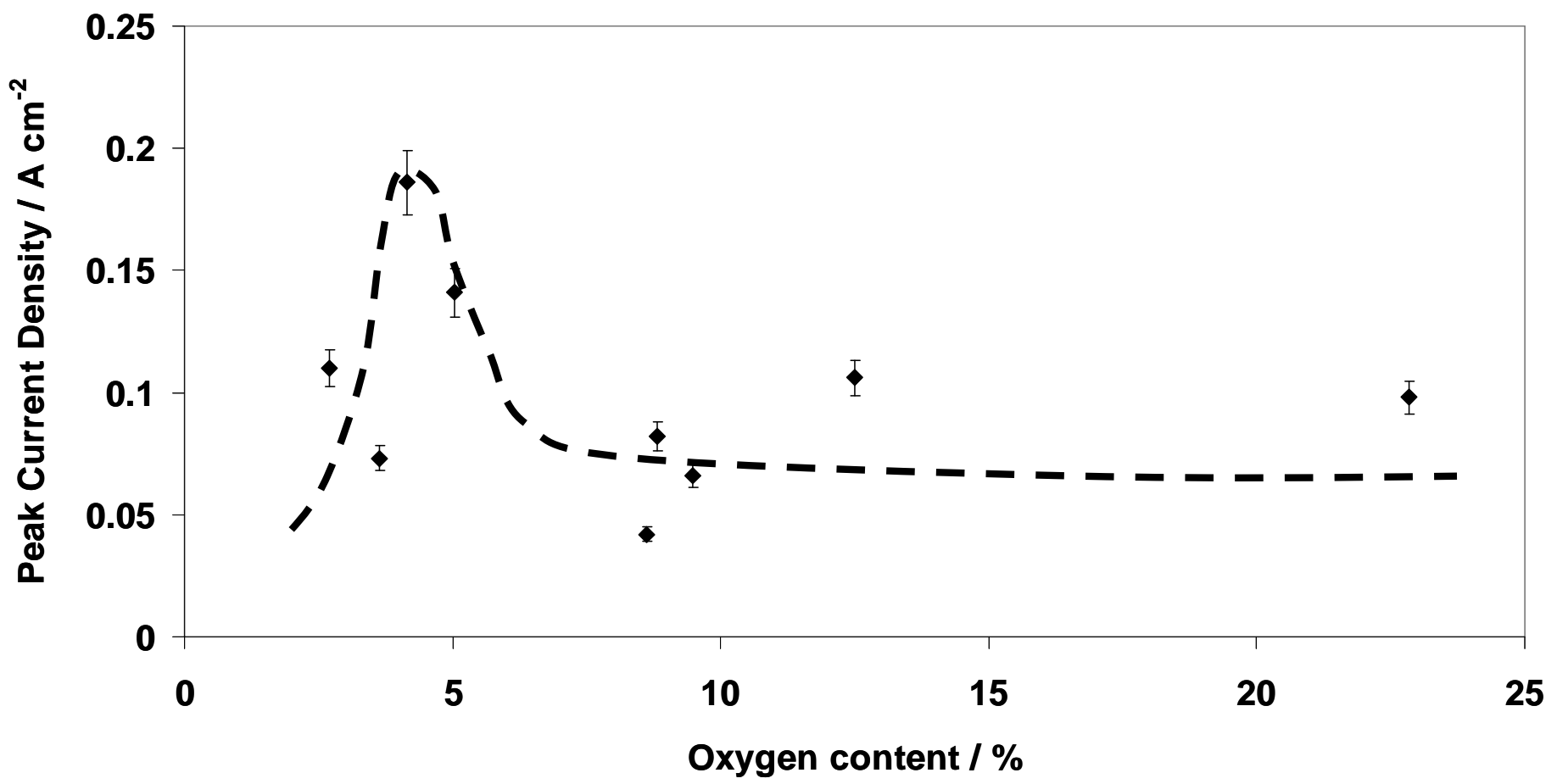

FIG. 18 